Check for updates

Cite this: RSC Adv., 2019, 9, 940

Received 17th November 2018 Accepted 13th December 2018

DOI: $10.1039 / c 8 r a 09471 c$

rsc.li/rsc-advances

\section{Fish-scale-derived carbon dots as efficient fluorescent nanoprobes for detection of ferric ions $\uparrow$}

\author{
Yi Zhang, ${ }^{\text {ab }}$ Zhiyong Gao, (D) *a Xue Yang, ${ }^{\text {b }}$ Jiuli Chang, ${ }^{\text {a }}$ Ziyan Liu ${ }^{\mathrm{c}}$ and Kai Jiang ${ }^{\star a d}$
}

Herein, highly fluorescent carbon dots (CDs) with the incorporation of $\mathrm{N}$ and $\mathrm{O}$ functionalities were prepared through a facile and cost-effective hydrothermal reaction using fish scales of the crucian carp as the precursor. The as-prepared CDs exhibit strong fluorescent emissions at $430 \mathrm{~nm}$ with a relative quantum yield of $6.9 \%$, low cytotoxicity, and robust fluorescence stability against photobleaching and good ionic strength. More significantly, the fluorescence of these CDs can be effectively and selectively quenched by $\mathrm{Fe}^{3+}$ ions, which enables the application of $\mathrm{CDs}$ as fluorescent $\mathrm{Fe}^{3+}$ nanoprobes with a linear range of $1-78 \mu \mathrm{mol} \mathrm{L} \mathrm{L}^{-1}$ and a detection limit of $0.54 \mu \mathrm{mol} \mathrm{L} \mathrm{L}^{-1}$. The proposed fluorescent $C D$ nanoprobes can also be used for the assay of spiked $\mathrm{Fe}^{3+}$ in real water samples and human serums with high recoveries and low standard deviations. Hence, CDs can be potentially applied as safe and reliable fluorescent nanoprobes for environmental and clinical $\mathrm{Fe}^{3+}$ analyses.
$\mathrm{Fe}^{3+}$ ions are a versatile chemical that have been widely used in the purification of drinking water, catalyzing certain reactions, ${ }^{1,2}$ and electronic industry. In addition, $\mathrm{Fe}^{3+}$ is also an essential metal ion in hemoglobin, myosin, and cytochrome, which can regulate normal oxygen uptake, cellular metabolism, and enzymatic reactions in physiological DNA and RNA syntheses in human bodies. ${ }^{3,4}$ The deficiency of $\mathrm{Fe}^{3+}$ causes various diseases such as iron deficiency, anemia, aplastic anemia, complicating further into limb weakness and reduced immune functions, ${ }^{5}$ whereas excessive $\mathrm{Fe}^{3+}$ can result in dysfunctions (kidney, heart, and liver), Alzheimer's disease, and even cancer. ${ }^{6-8}$ Hence, the accurate analysis of $\mathrm{Fe}^{3+}$ is of significant clinical importance. On the other hand, the overutilization of Fe resources and the discharge of $\mathrm{Fe}^{3+}$ containing sewage into aquatic environments result in a considerable threat to the natural environment; therefore, the accurate and reliable determination of $\mathrm{Fe}^{3+}$ in aquatic media is also imperative. ${ }^{9}$ Conventional $\mathrm{Fe}^{3+}$ detection

${ }^{a}$ School of Chemistry and Chemical Engineering, Collaborative Innovation Center of Henan Province for Green Manufacturing of Fine Chemicals, Key Laboratory of Green Chemical Media and Reactions, Ministry of Education, Henan Normal University, Xinxiang 453007, Henan, PR China. E-mail: zygao512@163.com; kjiang512@163.com

${ }^{b}$ School of Laboratory Medicine, Xinxiang Medical University, Xinxiang 453003, Henan, PR China

${ }^{c}$ Maternal and Child Care Service Centre of Xinxiang City, Xinxiang 453000, Henan, PR China

${ }^{d}$ School of Environment, Henan Normal University, Xinxiang 453007, Henan, PR China

$\dagger$ Electronic supplementary information (ESI) available: Fig. S1-S10. See DOI: $10.1039 / \mathrm{c} 8 \mathrm{ra} 09471 \mathrm{c}$ techniques mainly include flame atomic absorption spectrophotometry (FAAS) ${ }^{10}$ inductively coupled plasma mass spectrometry (ICP-MS), ${ }^{11}$ voltammetry, ${ }^{12}$ and spectrometry. ${ }^{13}$ Although worthwhile detection accuracy can be achieved, these techniques usually require tedious sample preparation procedures or sophisticated instruments, which limit the rapid and handy analysis of $\mathrm{Fe}^{3+}$ in practice. Hence, it is essential to develop cost-effective analysis means for the quantitative detection of $\mathrm{Fe}^{3+}$.

Because of its high sensitivity, rapid response, and simplicity in sample preparation, the fluorescent probe technique is recognized as an alternative means to quantitatively determine $\mathrm{Fe}^{3+}$ ions through fluorescence quenching interactions. ${ }^{14-16}$ Currently, the major fluorescent probe materials for $\mathrm{Fe}^{3+}$ detection include organic fluorescent dyes, ${ }^{17,18}$ noble metal nanoclusters, ${ }^{19,20}$ and heavy-metal chalcogenide semiconductor quantum dots. ${ }^{21,22}$ Nevertheless, organic fluorescent dyes suffer from photobleaching, and semiconductor quantum dots suffer from potential elemental toxicity and complicated size/ morphology control issues. Therefore, it is essential to investigate alternative fluorescent probes for the sensitive and rapid detection of $\mathrm{Fe}^{3+}$ with high photostability, low cytotoxicity, and easy availability that can be suitable for widespread applications.

Carbon quantum dots (CDs) represent a newly emerged fluorescent nanomaterial with the doping or decoration of heteroelements containing functionalities within/onto the tiny carbonaceous motif (below $10 \mathrm{~nm}$ ). ${ }^{23}$ Besides the high fluorescence intensity, CDs also exhibit high solubility, robust chemical inertness, high resistance toward photobleaching, 
and good biocompatibility; hence, CDs can serve as efficient and safe fluorescent nanomaterials for bioimaging, ${ }^{24}$ antifaking, ${ }^{25}$ biosensing, ${ }^{26}$ and photocatalysis. ${ }^{27}$ In particular, CDs can serve as electron donors in contact with guest acceptors through electrostatic or coordination interactions: the excitation state electrons of CDs can be nonradiatively transferred to the guest analytes, and therefore, the fluorescence of CDs is effectively quenched. Hence, CDs are widely investigated as credible sensing nanoprobes for the analyses of various guest ions/molecules with high sensitivities and reliabilities.

In general, CDs can be prepared through top-down and bottom-up strategies. The former approach mainly includes the chemical or electrochemical cutting of graphitic motifs (graphite, carbon nanotubes, or graphene) into tiny nanodots with tunable bandgaps, but this approach commonly necessitates harsh synthesis conditions and modification of functionalities to tune the electron structure, structural energy traps, and further the fluorescent activities. In contrast, the latter approach can more easily yield CDs through the pyrolysis, solvothermal, or wetchemical condensation of small molecular organics, polymers, and other easily available biomass low-cost raw materials, which cater toward the cost expectation for practical applications. Up to now, various natural biomass precursors, such as fruit juices, ${ }^{28-30}$ vegetables, ${ }^{31,32}$ grass, ${ }^{33}$ milk, ${ }^{34}$ beer, ${ }^{35}$ and even waste ${ }^{36}$ have been successfully employed to fabricate fluorescent CDs. Fish scale is a commonly discarded biomass waste containing rich proteins, which is considered to be a potential precursor for the costeffective preparation of CDs in a safe manner. The further utilization of the afforded fluorescent CDs as fluorescent nanoprobes for $\mathrm{Fe}^{3+}$ detection deserves to be investigated.

In this work, the easily available fish scales of the crucian carp was employed as a precursor for the hydrothermal synthesis of CDs. The afforded water-soluble CDs exhibit strong bluish fluorescence with a quantum yield (QY) of 6.9\%, high resistances against photobleaching, high ion strength, and low cytotoxicity. The fluorescence of CDs can be effectively quenched by $\mathrm{Fe}^{3+}$ ions via static quenching, which facilitates its application as fluorescent $\mathrm{Fe}^{3+}$ nanoprobes with a wide linear detection range and low detection limit. Such CD-based fluorescent $\mathrm{Fe}^{3+}$ nanoprobes can be further used in the determination of real water samples and human serum with high reproducibility, exhibiting their potential as reliable fluorescent nanoprobes for environmental and clinical $\mathrm{Fe}^{3+}$ detection.

\section{Experimental}

\section{Reagents}

Dulbecco's modified eagle medium (DMEM) and fetal bovine serum (FBS) were obtained from Gibco (USA). Common chemical reagents were of the analytical grade and directly used as received. Deionized (DI) water was used throughout the experiment. Britton-Robinson (BR) buffer solutions with different $\mathrm{pH}$ values were prepared by adding concentrated $\mathrm{NaOH}(0.2 \mathrm{M})$ to a $\mathrm{H}_{3} \mathrm{PO}_{4}-\mathrm{HAc}-\mathrm{H}_{3} \mathrm{BO}_{3}$ mixed acid solution (0.04 $\mathrm{M}$ each). Normal human serum samples were kindly provided by the local hospital (Xinxiang, China).

\section{Synthesis of CDs}

CDs were prepared by the hydrothermal treatment of the fish scale precursor. In brief, $1.0 \mathrm{~g}$ fish scales of the crucian carp (local supermarket, Xinxiang, China) was pulverized and dispersed in $40 \mathrm{~mL}$ DI water under vigorous stirring, followed by hydrothermal treatment in a Teflon-lined stainless steel autoclave at $200{ }^{\circ} \mathrm{C}$ for $20 \mathrm{~h}$. After being naturally cooled, the brownish dispersion was centrifuged at $3000 \mathrm{rpm}$ for $15 \mathrm{~min}$ to remove the sediment. The clear supernatant was dialyzed using a dialysis bag (molecular weight cutoff: $3500 \mathrm{Da}$ ) in DI for $48 \mathrm{~h}$. Finally, the purified CD solution was filtered using a $0.22 \mu \mathrm{m}$ membrane filter and freeze-dried for characterizations. The obtained brown product was dispersed in DI water to form a clear suspension with a concentration of $5 \mathrm{mg} \mathrm{mL}^{-1}$ for the subsequent fluorescent sensing measurements.

\section{Characterizations}

High-resolution transmission electron microscopy (HRTEM, JEOL JEM 2100) was used to obtain the microstructure of CDs. The functionalities of the CDs were characterized by using Fourier-transform infrared spectroscopy (FTIR, Thermo Nicolet FTS NEXUS: the sample was pressed in a KBr pellet). The phase and elemental statuses of the CDs were characterized by powder $\mathrm{X}$-ray diffraction (XRD, Bruker D8 diffractometer with $\mathrm{Cu}-\mathrm{K} \alpha$ incident radiation) and X-ray photoelectron spectroscopy (XPS, ESCALAB250, Thermo, UK). The UV-vis absorption spectra, fluorescence emission spectra, and time-resolved fluorescence spectra of the CD solution and $\mathrm{CD}-\mathrm{Fe}^{3+}$ system were recorded on UV-1700 spectrophotometer (Shimadzu), FP-6500 spectrophotometer (Hitachi), and FlS-980 fluorescence spectrometer (Edinburgh Instrument), respectively.

\section{Procedure for $\mathrm{Fe}^{3+}$ detection}

Typically, $200 \mu \mathrm{L} \mathrm{CD}$ dispersion $\left(5 \mathrm{mg} \mathrm{mL}^{-1}\right)$ was added in a test tube, followed by the addition of $1 \mathrm{~mL}$ BR buffer solution $(\mathrm{pH}=$ 7.0). Thereafter, standard $\mathrm{Fe}^{3+}$ solutions (0.001 and $0.01 \mathrm{M}$, diluted from $1.000 \mathrm{M}$ concentrated stock solution) with different volumes were added into the CD solution and then diluted to $4 \mathrm{~mL}$ with DI water. The detailed dosages of $\mathrm{Fe}^{3+}$ are listed in Table S1. $\uparrow$ The solution was shaken at room temperature for $5 \mathrm{~min}$ for fluorescent measurement at the excitation wavelength $\left(\lambda_{\text {ex }}\right)$ of $350 \mathrm{~nm}$. The interferents of inorganic ions and biomolecules were also added to the CD solution instead of $\mathrm{Fe}^{3+}$ and the fluorescence spectra were recorded at $\lambda_{\text {ex }}=$ $350 \mathrm{~nm}$.

\section{Analysis of real samples}

To evaluate the feasibility of CD-based fluorescent nanoprobes for $\mathrm{Fe}^{3+}$ detection in real aquatic media or serum samples, the water samples (collected from Xinxiang China) were filtered through a $0.22 \mathrm{~m}$ membrane (Millipore) and used as the solvent. Aliquots $(1 \mathrm{~mL})$ of the filtered water sample spiked with standard $\mathrm{Fe}^{3+}$ ion solutions (final concentrations: 8 and $12 \mu \mathrm{mol}$ $\left.\mathrm{L}^{-1}\right)$ were diluted to $4 \mathrm{~mL}$ with the BR buffer solution $(\mathrm{pH}=7.0)$ and CD solution (final concentration of CDs: $250 \mathrm{mg} \mathrm{mL}{ }^{-1}$ ). 
Then, the PL intensities of the spiked solutions were measured. With regard to the serum sample, the normal human serum sample from a local hospital (Xinxiang, China) was directly used for determining the concentration of the spiked $\mathrm{Fe}^{3+}$ in a similar manner.

\section{Cytotoxicity assays}

PC-12 (pheochromocytoma of the rat adrenal medulla) cells were cultured in DMEM containing 5\% FBS under $5 \% \mathrm{CO}_{2}$ atmosphere at $37{ }^{\circ} \mathrm{C}$, which was used to evaluate cell toxicity. The cell viability was measured using the MTT (3-(4,5-dimethyl2-2thiazolyl)-2,5-diphenyl-2 $H$-tetrazolium bromide) assay. In brief, $5 \times 10^{5}$ cells $(100 \mu \mathrm{L})$ were incubated with CDs $(40,100$, 200,300 , and $400 \mu \mathrm{g} \mathrm{mL} \mathrm{m}^{-1}$ ) in quadruplicates in a 96-well plate for $24 \mathrm{~h}$ at $37{ }^{\circ} \mathrm{C}$; cells treated with dimethyl sulfoxide alone were used as a comparison. Thereafter, $10 \mu \mathrm{L} \mathrm{MTT}\left(5 \mathrm{mg} \mathrm{mL}^{-1}\right)$ was added to each well and incubated for an additional $4 \mathrm{~h}$ at $37^{\circ} \mathrm{C}$. The absorbance in the presence and absence of CDs were measured at $570 \mathrm{~nm}$ for the calculation of cell viability. ${ }^{37}$ The cell viability can be expressed as follows:

$$
\text { Cell viability }(\%)=\frac{A_{\text {sample }}}{A_{\text {control }}} \times 100 \%
$$

\section{QY measurements}

The QY values of CDs were determined by comparing the integrated fluorescence area $\left(\lambda_{\mathrm{ex}}=350 \mathrm{~nm}\right)$ at per unit absorbance (at $350 \mathrm{~nm}$ ) of CDs using quinine sulfate dissolved in $0.1 \mathrm{M}$ $\mathrm{H}_{2} \mathrm{SO}_{4}$ as the standard $(\mathrm{QY}=0.54)$. The $\mathrm{QY}$ value was calculated using the equation $\mathrm{QY}_{\mathrm{x}}=\mathrm{QY}_{\mathrm{ST}}\left(F_{\mathrm{x}} / F_{\mathrm{ST}}\right)\left(A_{\mathrm{x}} / A_{\mathrm{ST}}\right)\left(\lambda_{\mathrm{x}} / \lambda_{\mathrm{ST}}\right)\left(\eta_{\mathrm{x}} / \eta_{\mathrm{ST}}\right)^{2} .^{15}$ Here, $F$ is the integral area of the fluorescence emission spectra, $A$ is the absorbance, $\lambda$ is the fluorescence excitation wavelength, $\eta$ is the refractive index of the solvent, and the subscripts ST and $\mathrm{x}$ represent the reference quinine sulfate and CD samples, respectively. In order to minimize the reabsorption effect, the absorbance was maintained below 0.05 .

\section{Cellular imaging}

KG-1a cells were cultured and maintained in DMEM. The media were supplemented with $5 \%$ FBS. The cells were maintained at $37^{\circ} \mathrm{C}$ and in a humidified atmosphere with $5 \% \mathrm{CO}_{2}$. KG-1a cells were trypsinized and seeded in tissue culture plates at $5 \times 10^{5}$ cells per well. After overnight incubation inside a humidified $5 \% \mathrm{CO}_{2}$ incubator for cell attachment, the cells were incubated with CDs for $24 \mathrm{~h}$. After washing five times with fresh phosphate buffer solution, fluorescence microscopy images were recorded with an inverted fluorescence microscope (Nikon Eclipse Ti-S) within a $\lambda_{\text {ex }}$ range of $320-450 \mathrm{~nm}$.

\section{Results and discussion}

\section{Characterizations}

Fish scales are often discarded biomass waste in our daily diet, but they contain rich nourishments including collagen protein, fat, and vitamins; $;^{38,39}$ hence, fish scales are valuable and easily available precursors for transforming into useful carbonaceous materials through carbonization treatments. In this work, fish scales of the crucian carp were attempted for use as a precursor for the preparation of CDs in order to realize resource reutilization. Under hydrothermal treatment at $200{ }^{\circ} \mathrm{C}$ for $20 \mathrm{~h}$, the peptide chains of collagen and other organic ingredients experience partial hydrolytic cleavage, dehydrogenation, and dehydroxylation reactions to afford reactive radical intermediates. ${ }^{\mathbf{4 0 , 4 1}}$ The condensation and cyclic rearrangement of these radicals, namely, their carbonization at high temperatures, yields an aromatic carbon framework, as intuitively evidenced from the brownish color of the CD solution. On the other hand, the residual polar functionalities onto the carbonaceous motif impart the CDs with high surface polarity or hydrophilicity, which enables its excellent solubility in aqueous media. Upon irradiation by ultraviolet light, this aqueous CD solution exhibits light bluish fluorescence, showing a robust fluorescent property. The preparation process of fish-scalederived CDs is summarized in Fig. 1.

The morphology and microstructure of the as-prepared CDs are shown in Fig. 2a. As observed, the approximately spherical CD particles with a size of 5-10 $\mathrm{nm}$ free of severe aggregation exhibit good dispersity. Fig. 2b shows the HRTEM image of the individual CDs: all the CDs demonstrate low contrast against

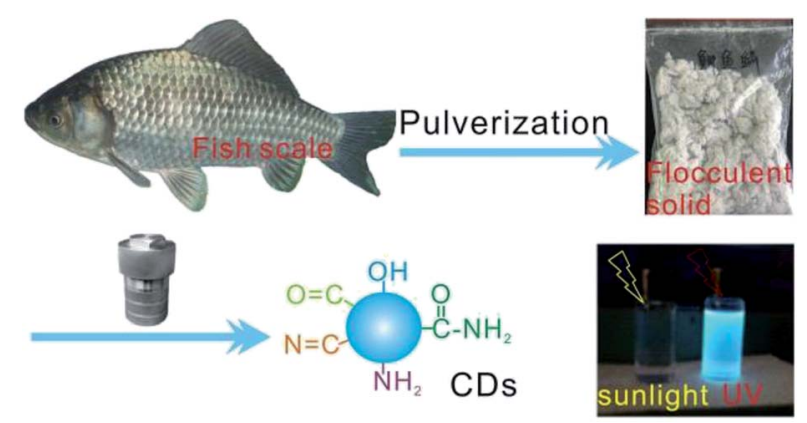

Fig. 1 Schematic illustration for the preparation of fish-scale-derived CDs.

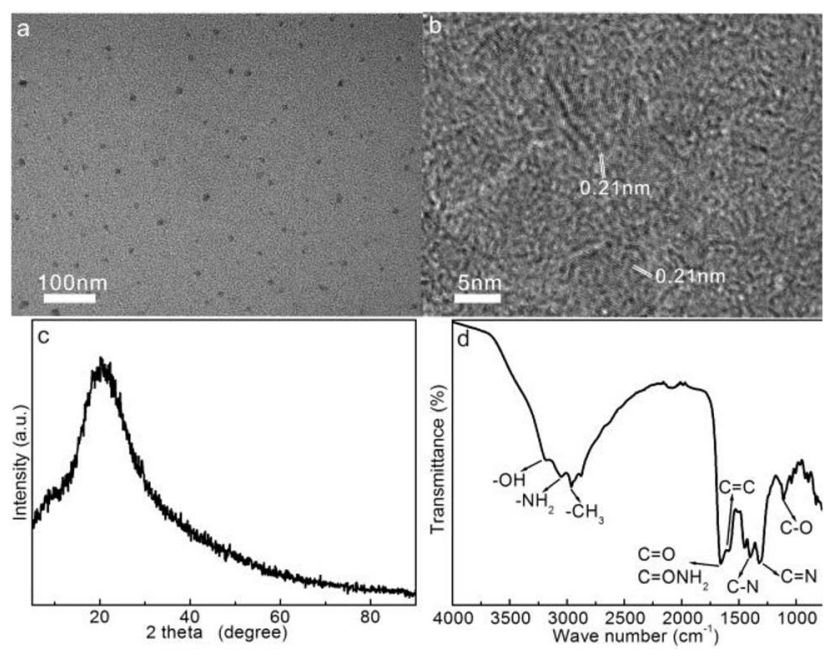

Fig. 2 (a) TEM, (b) HRTEM, (c) XRD, and (d) FTIR spectra of the CDs. 
the background, which is mainly due to the tiny size and low atomic weights of skeletal $\mathrm{C}$ and doped $\mathrm{N}$ atoms against the electron beam; the easy penetration of the electron beams across the CDs induce high transmittance. In addition, wellresolved lattice fringes with a spacing of $0.21 \mathrm{~nm}$ can be observed within the CDs, which correspond to the (100) planes diffraction of the graphitic carbon framework, ${ }^{\mathbf{4 2}}$ revealing the easy carbonization of the fish scale precursors. These results indicate the successful carbonization of the nourishment components in fish scales to form a graphitic microstructure within the CDs.

Fig. $2 c$ shows the XRD pattern of freeze-dried CD solids. The wide diffraction peak centered at $20.5^{\circ}$ corresponds to the (002) planes of the graphitic carbon structure with an interlayer $d$ value of $0.43 \mathrm{~nm}$. The larger spacing over graphite $(0.336 \mathrm{~nm})$ is presumably due to the weaker aromatic stacking interaction of the graphitic carbon framework owing to the low graphitization degree and abundant $\mathrm{N}$ and $\mathrm{O}$ functionalities around the CDs. $^{\mathbf{4 3 4 4}}$ Overall, the weak diffraction intensity and broadness of the peak suggest the amorphous phase of CDs induced by the hydrothermal carbonization of fish scales.

The FTIR spectrum of CDs was characterized to reveal the chemical functionalities within the CDs, as shown in Fig. $2 \mathrm{~d}$. The peak at $1640 \mathrm{~cm}^{-1}$ corresponds to the $\mathrm{C}=\mathrm{O}$ and $\mathrm{CONH}_{2}$ stretching vibrations. ${ }^{45}$ The three bands around 3200,3060 , and $2960 \mathrm{~cm}^{-1}$ are associated with the $-\mathrm{OH},-\mathrm{NH}_{2}$, and $-\mathrm{CH}_{3}$ groups, respectively. ${ }^{\mathbf{4 6 , 4 7}}$ In addition, the characteristic IR vibrations at $1596,1395 \mathrm{~cm}^{-1}$, and $1310 \mathrm{~cm}^{-1}$ can be assigned to the $\mathrm{C}=\mathrm{C}, \mathrm{C}-\mathrm{N}$, and tertiary $\mathrm{C}=\mathrm{N}$ stretching vibrations, respectively,,$^{42,47}$ and the peak at $1106 \mathrm{~cm}^{-1}$ is attributable to the stretching vibrations of the $\mathrm{C}-\mathrm{O}$ groups within the CDs. ${ }^{\mathbf{4 2 , 4 8}}$ All these vibrations preliminarily indicate the presence of enriched $-\mathrm{OH} /-\mathrm{NH}_{2}$, carbonyl, and amide functionalities onto the aromatic $\mathrm{C}=\mathrm{C} / \mathrm{C}=\mathrm{N}$ framework. These abundant polar functionalities enable high hydrophilicity and stability of CDs in an aqueous medium.

The chemical status of the CDs was characterized by XPS. From the survey spectrum (Fig. 3a), it is evident that the CDs display three distinct peaks at 285, 400, and $531 \mathrm{eV}$, which are, in turn, assignable to the $\mathrm{C} 1 \mathrm{~s}, \mathrm{~N} 1 \mathrm{~s}$, and $\mathrm{O} 1 \mathrm{~s}$ orbits, respectively, showing the carbonaceous framework with the doping/ decoration of $\mathrm{N}$ and $\mathrm{O}$ groups. The atomic fractions of $\mathrm{C}, \mathrm{N}$, and $\mathrm{O}$ are 70,14 , and $16 \%$, respectively, in CDs, indicating the enriched $\mathrm{N}$ and $\mathrm{O}$ functionalities within/onto the carbon motif. To additionally identify the elemental form, the C $1 \mathrm{~s}, \mathrm{~N} 1 \mathrm{~s}$, and $\mathrm{O} 1 \mathrm{~s}$ peaks were deconvoluted and fitted. As shown in Fig. 3b, the $\mathrm{C}$ 1s spectrum of $\mathrm{CDs}$ comprises skeletal $\mathrm{C}=\mathrm{C} / \mathrm{C}-\mathrm{C}(284.5$ $\mathrm{eV})$ bonds and $\mathrm{C}-\mathrm{N} / \mathrm{C}-\mathrm{O}(285.1 \mathrm{eV}), \mathrm{C}-\mathrm{O} / \mathrm{C}=\mathrm{N}(286.1 \mathrm{eV})$, and $\mathrm{C}=\mathrm{O}(288.1 \mathrm{eV})$ functionalities, ${ }^{47,49}$ revealing the enriched $\mathrm{N}$ and $\mathrm{O}$ functionalities onto the graphitic framework. Moreover, the $\mathrm{N}$ 1s peak (Fig. 3c) can be fitted into $\mathrm{C}-\mathrm{N}-\mathrm{C}(399.6 \mathrm{eV})$ and $\mathrm{N}-\mathrm{H}$ bonds $(400.2 \mathrm{eV}){ }^{50}$ revealing that the $\mathrm{N}$ element mainly exists in the form of amino groups and doped carbonaceous framework. The $\mathrm{O} 1 \mathrm{~s}$ spectrum (Fig. 3d) fitting result indicates the decoration of $\mathrm{C}=\mathrm{O}(531.2 \mathrm{eV})$ and $\mathrm{C}-\mathrm{OH} / \mathrm{C}-\mathrm{O}-\mathrm{C}(532.1 \mathrm{eV})$ groups onto the carbonaceous framework. ${ }^{51}$ All these functionalities identified by the XPS basically coincide with the FTIR
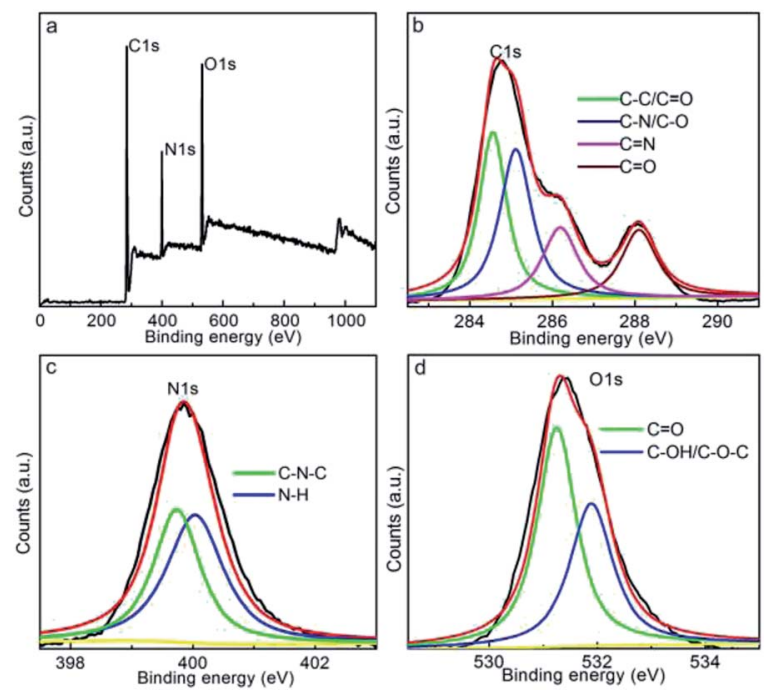

Fig. 3 (a) XPS, (b) C 1s, (c) N 1s, and (d) $O$ 1s spectra of CDs.

results, proving the decoration of amine, amide, hydroxyl, and carbonyl groups onto the $\mathrm{N}$-incorporated carbonaceous framework. The multiple $\mathrm{N}$ and $\mathrm{O}$ groups onto the CDs promote high hydrophilicity and further the formation of stable aqueous solutions, suitable for realizing long-term preservative-free precipitate that can be beneficial in practical applications. In addition, these single- and double-bonded functional groups can function as auxochromes/chromophores, ensuring fluorescent emissions or stabilizing surface-defect-associated emission energy traps: both these factors are beneficial toward facilitating high fluorescent activity of CDs.

\section{Optical properties of CDs}

The UV-vis absorption spectrum of the aqueous CD solution (Fig. 4a) exhibits distinct absorbance in the UV region. The obvious absorption plateau at $263 \mathrm{~nm}$ is mainly assigned to the $\pi-\pi^{*}$ transition of the skeletal aromatic carbon rings and double bonds. ${ }^{52}$ In addition, another obvious background within $300-350 \mathrm{~nm}$ is associated with the $\mathrm{n}-\pi *$ transition of the double bonds with groups such as $\mathrm{C}=\mathrm{O}, \mathrm{C}=\mathrm{N}$, and $\mathrm{CONH}_{2} \cdot{ }^{53,54}$ These characteristic absorptions reflect the aromatic carbonaceous motif and coexistence of double-bond-containing functionalities, which can serve as chromophores or auxochromes, reinforcing the fluorescence emissions of CDs. The fluorescent properties were initially evaluated under excitation at $\lambda_{\text {ex }}=350$ and $700 \mathrm{~nm}$, as shown in Fig. 4b. The aqueous CD solution exhibits strong fluorescence emissions centered at $440 \mathrm{~nm}$, showing both down-conversion and up-conversion fluorescence behaviors. These characteristics indicate that the fluorescence emission can be triggered by high-energy photons (downconversion) and multiple low-energy photons (up-conversion). Under excitation at $350 \mathrm{~nm}$, the relative QY of the CD solution can be calculated as $6.9 \%$, yielding high fluorescence activity.

The $\lambda_{\text {ex }}$ dependence of CDs can primarily reveal the origins of the fluorescence behavior, as shown in Fig. 4c. As $\lambda_{\text {ex }}$ increases from 220 to $290 \mathrm{~nm}$, the emission intensity gradually increases, 

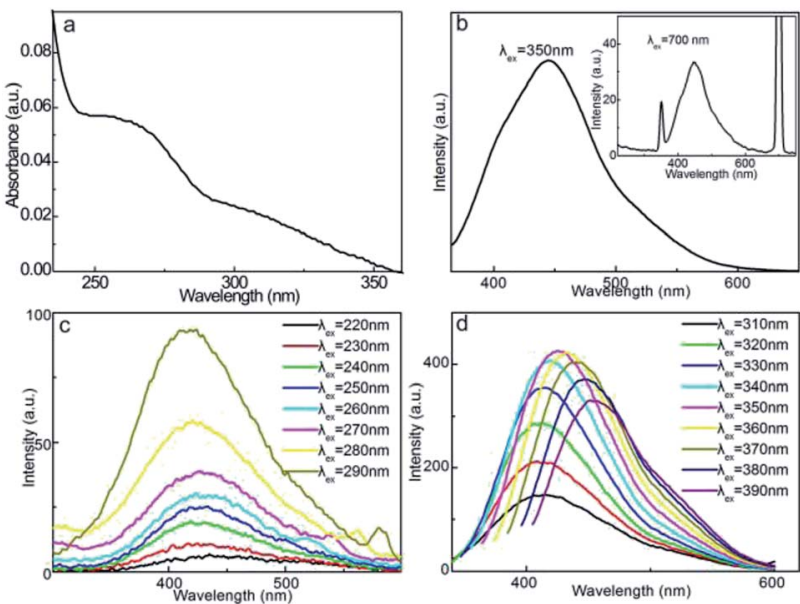

Fig. 4 (a) UV-vis absorption spectrum, (b) fluorescence emission spectra of CDs at $\lambda_{\text {ex }}=350$ and $700 \mathrm{~nm}$ (inset), $C_{\mathrm{CDs}}=25 \mu \mathrm{g} \mathrm{mL}^{-1}$. Fluorescence spectra of CDs within $\lambda_{\text {ex }}$ range of (c) $220-290 \mathrm{~nm}$ and (d) $310-390 \mathrm{~nm}, C_{\mathrm{CDs}}=125 \mu \mathrm{g} \mathrm{mL}^{-1}$.

but the emission wavelength $\left(\lambda_{\mathrm{em}}\right)$ remains almost unaltered at $425 \mathrm{~nm}$. This portion of $\lambda_{\mathrm{ex}}$-independent emission behavior is presumably related to the carbonyl, amide, and imine chromophores. ${ }^{55}$ The almost constant ground state-excitation state energy gap of these double-bond functionalities is responsible for this invariable $\lambda_{\mathrm{em}}$. In contrast, a further increase in $\lambda_{\mathrm{ex}}$ from 310 to $390 \mathrm{~nm}$ induces gradual red-shifts in $\lambda_{\text {em }}$ from 430 to $455 \mathrm{~nm}$ (Fig. 4d). The maximum emission intensity is achieved at $\lambda_{\mathrm{em}}=440 \mathrm{~nm}$ upon excitation at $\lambda_{\mathrm{ex}}=350 \mathrm{~nm}$, revealing the obvious $\lambda_{\text {ex }}$-dependent fluorescence behavior. This portion of the $\lambda_{\text {ex }}$-dependent fluorescence behavior is presumably derived from the surface state and size-dependent optical selection of CDs. ${ }^{42,56}$ The different charge recombination energies of the individual CD particles yield different emission energies, and therefore, different $\lambda_{\mathrm{em}}$ values. In addition, particles with smaller sizes generally emit at shorter $\lambda_{\mathrm{em}}$ values for larger bandgaps, while larger particles emit at longer $\lambda_{\text {em }}$ values; this factor also causes different excitation energies of different CDs, and therefore, the $\lambda_{\text {ex }}$-dependent fluorescence behavior. The combined $\lambda_{\text {ex }}$-independent and $\lambda_{\text {ex }}$-dependent behaviors prove that dual fluorescence mechanisms are involved in downconversion fluorescence emissions. Moreover, CDs also exhibit weak up-conversion fluorescence behavior with $\lambda_{\text {ex }}$ varying within 560-740 $\mathrm{nm}$ with the maximum emission intensity at $\lambda_{\mathrm{em}}=440 \mathrm{~nm}$ upon excitation at $\lambda_{\mathrm{ex}}=700 \mathrm{~nm}$ (Fig. S1 $\dagger$ ). The $\lambda_{\text {ex }}$-dependent up-conversion emission excludes the anti-Stokes emission mechanism; therefore, it is hypothesized that the emission of CDs is caused by the excitation of two or more low-energy photons to sustain the electron transitions to the excitation state, and therefore, the emission of highenergy photons, namely, the multi-photon mechanism. ${ }^{57}$

The fluorescence emission spectra at different CD concentrations were also measured upon excitation at $\lambda_{\mathrm{ex}}=350 \mathrm{~nm}$ (Fig. 5a): the emission intensity increases proportionally with the $\mathrm{CD}$ concentration up to $250 \mu \mathrm{g} \mathrm{mL} \mathrm{m}^{-1}$. The strong PL behavior and good linearity enable the application of CDs as fluorescent probes for the quantitative analysis of analytes at
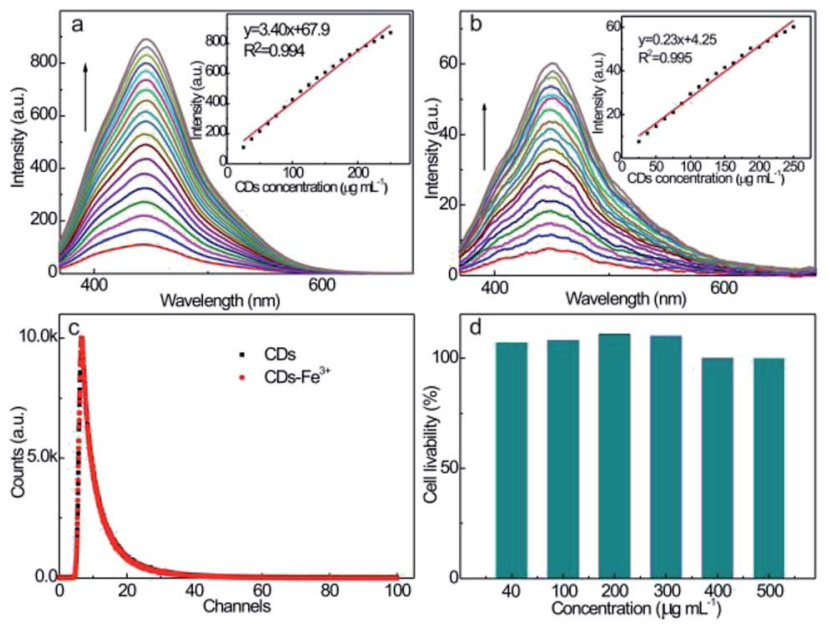

Fig. 5 Fluorescence spectra of aqueous CD solutions with different concentrations at (a) $\lambda_{\mathrm{ex}}=350 \mathrm{~nm}$ and (b) $\lambda_{\mathrm{ex}}=700 \mathrm{~nm}$. Inset: emission intensity vs. CD concentration plots. CD concentration: 25 , $37.5,50,62.5,75,87.5,100,112.5,125,137.5,150,162.5,175,187.5$, $200,212.5,225,237.5$, and $250 \mu \mathrm{g} \mathrm{mL}^{-1}$. (c) Fluorescence decay curves of aqueous $C D$ and $C D-F^{3+}$ systems. (d) Livability of PC-12 cells incubated at different CDs concentrations.

various concentrations without scrupling the self-quenching effect. The good linearity between the up-conversion emission intensity $\left(\lambda_{\mathrm{ex}}=700 \mathrm{~nm}\right)$ and CD concentration (Fig. 5b) also suggests the feasibility as fluorescent probes. Considering the much higher emission intensity, the down-conversion emission feature is more suitable for the fluorescence sensing of guest quenchers with higher sensitivity.

The fluorescence decay property of the CD solution at $\lambda_{\mathrm{ex}}=$ $350 \mathrm{~nm}$ is revealed by the time-resolved fluorescence spectrum (Fig. 5c). The fluorescence of the CD solution exhibits doubleexponential decay kinetic behavior with $\tau_{1}$ of 2.84 ns and $\tau_{2}$ of $8.86 \mathrm{~ns}$, and their relative fractions are 43.7 and $56.3 \%$, respectively. According to the double exponential simulation, the average fluorescence lifetime of CDs is calculated to be $6.2 \mathrm{~ns}$, revealing a robust PL property as a consequence of the coupled surface energy traps, bandgap, and surface chromophores' fluorescence emission manners, which allow the rapid radiative recombination of the excitation state electrons. Upon incubation with $\mathrm{Fe}^{3+}$ quenchers, the fluorescence decay trend of the $\mathrm{CD}-\mathrm{Fe}^{3+}$ system almost completely overlaps with that of the initial CDs solution, and the average fluorescence lifetime of the $\mathrm{CD}-\mathrm{Fe}^{3+}$ system hardly alters (6.3 ns), revealing that the $\mathrm{Fe}^{3+}$ ions do not influence the relaxation time of the excitation state electrons of CDs.

To further examine the cytotoxicity of CDs, MTT assays were performed using PC-12 cells as the representative model. As shown in Fig. 5d, over 95\% of the PC-12 cells can still survive upon incubation with CDs over a wide concentration range of 40-500 $\mu \mathrm{g}$ $\mathrm{mL}^{-1}$ for $24 \mathrm{~h}$. This high cell viability confirms the negligible cytotoxicity and superior biocompatibility. The low cytotoxicity of the as-prepared CDs enables its clinical applications as a safe, fluorescent nanoprobe for monitoring $\mathrm{Fe}^{3+}$ in bodily fluids.

Considering the robust fluorescence characteristics with low cytotoxicity, CDs can also be used in cellular imaging. It was attempted to use KG-1a cells as the model to assess the 
feasibility of using CDs in intracellular bioimaging. Fig. 6 shows the optical microscopy and fluorescent microscopy images of CD-dyed KG-1a cells. In relation to the optical image (Fig. 6a), light blue fluorescence was observable in the intracellular region of the cells (Fig. 6b), showing the successful internalization of CDs into the cells. Hence, CDs can be used as optical labels for in vitro cellular imaging. Furthermore, CD-dyed KG-1a cells were cultivated with exogenous $\mathrm{Fe}^{3+}$ for $2 \mathrm{~h}$. The fluorescence of KG-1a cells cannot be discerned from Fig. 6c and d, which preliminarily suggests that our CDs can be employed as nanoprobes for the analysis of intracellular $\mathrm{Fe}^{3+}$ through quenching interactions. All these results indicate that CDs are membrane-permeable and can serve as potential intracellular $\mathrm{Fe}^{3+}$ imaging probes.

\section{Optimization of assay conditions}

Resistance against photobleaching is a worthwhile prerequisite for applications as reliable fluorescent nanoprobes. To facilitate photostability, an aqueous CD solution was exposed to continuous irradiation at $\lambda_{\mathrm{ex}}=350$ and $700 \mathrm{~nm}$ for different time courses (Fig. S2 $\dagger$ ). The emission intensities hardly decay upon irradiation up to $120 \mathrm{~min}$, suggesting the robust photostability of CDs, which sustains the fluorescence sensing of guest quenchers with good endurability to incident light. Moreover, the down-conversion and up-conversion emission intensities of CDs are rather stable at different ionic strengths (aqueous $\mathrm{NaCl}$ solutions within the concentration range of 0-125 mM) (Fig. S3 $\dagger$ ), suggesting that these CDs are highly stable against ionic strength, which is essential for the accurate sensing of analytes in real water samples that generally contain trace mineral components. Common biomolecules such as amino acids, DNA, and glucose cannot cause obvious fluorescence attenuation of CDs (Fig. S4†), which are also beneficial for the detection of guest quenchers in different bodily fluid samples with slight differences in the components. Furthermore, different inorganic ions were introduced into the aqueous CD solution: the fluorescence emission intensity remains unvaried when the main group ions, common transition metal ions (such as $\mathrm{Zn}^{2+}, \mathrm{Cd}^{2+}, \mathrm{Co}^{2+}$, and $\mathrm{Mn}^{2+}$ ions), and common anions (such

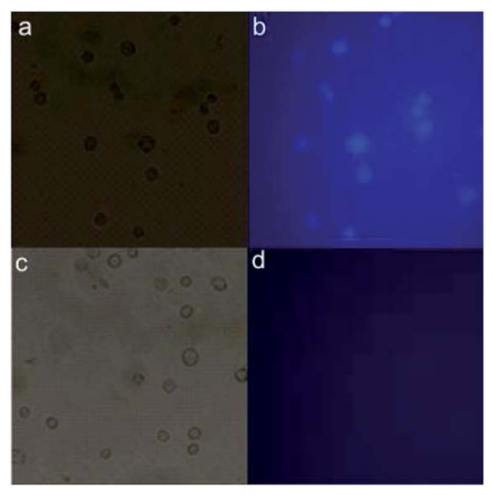

Fig. 6 ( $a$ and c) Optical microscopy and (b and d) fluorescence microscopy images of KG-1a cells incubated with $125 \mu \mathrm{g} \mathrm{mL}^{-1} \mathrm{CDs}$ for $24 \mathrm{~h}$ at $37^{\circ} \mathrm{C}$ in the ( $\mathrm{a}$ and b) absence and ( $\mathrm{c}$ and d) presence of $\mathrm{Fe}^{3+}$ $\left(2.5 \mu \mathrm{mol} \mathrm{L}{ }^{-1} \mathrm{FeCl}_{3}\right)$. as $\mathrm{Cl}^{-}, \mathrm{SO}_{4}{ }^{2-}$, and $\mathrm{NO}_{3}{ }^{-}$ions $)\left(100 \mu \mathrm{mol} \mathrm{L}{ }^{-1}\right)$ are introduced. These ions cannot quench the fluorescence of CDs, whereas $\mathrm{Ag}^{+}, \mathrm{Cu}^{2+}$, and $\mathrm{Ni}^{2+}$ cause a weak quenching effect on the fluorescence of CDs (Fig. S5 $\dagger$ ). It is also worthwhile to mention that $\mathrm{Fe}^{3+}$ obviously quenches the emission of CDs, which implies the highly selective fluorescent response of CDs toward $\mathrm{Fe}^{3+}$. Therefore, CDs can find applications in the selective detection of $\mathrm{Fe}^{3+}$ in aquatic environment or bodily fluid samples. The effect of $\mathrm{pH}(2-11)$ on the fluorescence spectrum of CDs was also investigated (Fig. S6 $\dagger$ ). The fluorescence intensity of CDs is maintained at a high and stable level in the $\mathrm{pH}$ range of 2-7, so $\mathrm{pH}=7$ is employed as the optimal environment for the construction of a fluorescence-sensing platform.

Considering the worthwhile fluorescent activity, excellent resistance against photobleaching, ion strength in a neutral $\mathrm{pH}$ medium, and sensitive fluorescence response toward $\mathrm{Fe}^{3+}$, asprepared CDs can be promising fluorescent nanoprobes for the quantitative detection of $\mathrm{Fe}^{3+}$. Fig. S7† shows the effect of CD concentration on the fluorescence emission intensity of CD$\mathrm{Fe}^{3+}$ system with a fixed $\mathrm{Fe}^{3+}$ concentration of $2.5 \mu \mathrm{mol} \mathrm{L}{ }^{-1}$. After the incorporation of $\mathrm{Fe}^{3+}$, the apparent decrement in the fluorescence intensity indicates that $\mathrm{Fe}^{3+}$ effectively quenches the fluorescence emission of CDs, and the fluorescence quenching extent depends on the CD concentration. At higher CD concentrations, the quenching extent $\left(\Delta F=F_{0}-F\right)$ increases. The increased sensitivity toward $\mathrm{Fe}^{3+}$ is mainly due to the additional sufficient quenching interactions between $\mathrm{Fe}^{3+}$ and CDs. When the CD concentration increases to $250 \mu \mathrm{g} \mathrm{mL} L^{-1}$, $\Delta F$ is the largest. To balance the detection accuracy and CD dosage, $250 \mu \mathrm{g} \mathrm{mL}{ }^{-1}$ was selected as the optimal concentration of $\mathrm{CDs}$ for $\mathrm{Fe}^{3+}$ detection.

The effect of the type of buffer solution on CD-based fluorescent nanoprobes for $\mathrm{Fe}^{3+}$ detection was also investigated. The relative fluorescence emission intensities of $\mathrm{CD}-\mathrm{Fe}^{3+}$ systems in $1 \mathrm{~mL} \mathrm{Na} \mathrm{HPO}_{4}$-citric acid, $\mathrm{BR}, \mathrm{NaH}_{2} \mathrm{PO}_{4}-\mathrm{Na}_{2} \mathrm{CO}_{3}$, and $\mathrm{KH}_{2} \mathrm{PO}_{4}-\mathrm{NaOH}$ buffer solutions $(\mathrm{pH}=7.0)$ were compared. As shown in Fig. S8a, $\dagger$ the BR buffer solution system exhibits the strongest fluorescence intensities and the largest $\Delta F$ value; these results indicate that BR is the optimal buffer medium for the fluorescence analysis for $\mathrm{Fe}^{3+}$ with higher sensitivity. The effect of the BR buffer solution concentration on $\Delta F$ values of $\mathrm{CD}-\mathrm{Fe}^{3+}$ detection systems was also investigated (Fig. S8b $\dagger$ ). The fluorescence intensities of the $\mathrm{CD}$ and $\mathrm{CD}-\mathrm{Fe}^{3+}$ systems changed marginally in the range of $0.5-2.0 \mathrm{~mL}$, whereas the $\Delta F$ value is larger and stable in the $1.0 \mathrm{~mL}$ buffer system; therefore, $1.0 \mathrm{~mL}$ BR buffer solution dosage was employed for $\mathrm{Fe}^{3+}$ detection. Based on the abovementioned optimization trials, CDs in $1.0 \mathrm{~mL}$ BR buffer solution at $\mathrm{pH}=7.0$ were employed as the preferred auxiliary medium for the fluorescent detection of $\mathrm{Fe}^{3+}$.

In order to study the reproducibility of CD-based fluorescent nanoprobes for $\mathrm{Fe}^{3+}$ detection, the fluorescence spectra of the $\mathrm{CD}-\mathrm{Fe}^{3+}$ system was repeatedly recorded by conducting eleven parallel trials. The relative standard deviation of $0.37 \%$ suggests the good reproducibility of CD-based fluorescent nanoprobes for $\mathrm{Fe}^{3+}$ analyses (Fig. S9†). 


\section{Calibration curve and detection limit}

The fluorescence emission spectra of CDs at different $\mathrm{Fe}^{3+}$ ion quencher concentrations are shown in Fig. 7a. Upon excitation at $\lambda_{\mathrm{ex}}=350 \mathrm{~nm}$, the emission intensity decreases according to the concentration of $\mathrm{Fe}^{3+}$ ions, showing efficient fluorescence quenching of CDs at higher $\mathrm{Fe}^{3+}$ ion concentrations. Moreover, no discernible changes in the peak wavelength or shape of the emission spectrum accompanied the quenching effect, suggesting a strong interaction between $\mathrm{Fe}^{3+}$ and surface functionalities (hydroxyl and amine groups) on the CDs. This induces the nonradiative electrons to transfer from the excited state of CDs to the half-filled $3 \mathrm{~d}$ orbits of $\mathrm{Fe}^{3+}, 53,58$ which, therefore, interrupts the radiative transition of electrons to the ground state to accomplish electron-hole pair recombinations, namely, the fluorescence quenching effect. From Fig. 7b, the fluorescence emission intensity of $\mathrm{CD}-\mathrm{Fe}^{3+}$ system decreases monotonously with an increase in the concentration of $\mathrm{Fe}^{3+}$ up to $488 \mu \mathrm{mol} \mathrm{L}{ }^{-1}$, showing the possession of rich interaction sites on the CDs. It should be noted that the emission intensity of the $\mathrm{CD}-\mathrm{Fe}^{3+}$ system exhibits good linearity within the $\mathrm{Fe}^{3+}$ concentration range of 1-78 $\mu \mathrm{mol} \mathrm{L} \mathrm{L}^{-1}$, which implies that CDs can serve as credible fluorescent nanoprobes for the quantitative detection of trace $\mathrm{Fe}^{3+}$ ions. It should also be noted that the decreased slope over this $\mathrm{Fe}^{3+}$ concentration range is presumably associated with the formation of $\mathrm{Fe}(\mathrm{OH})_{3}$, which suppresses the fluorescence response of CDs. ${ }^{59}$ From the inset, it is evident that a good linear response was observed at the square of the correlation coefficient $\left(R^{2}\right)$ value of 0.998 . The regression equation is as follows: $\Delta F=3.46+16.24[\mathrm{Q}]\left(\mu \mathrm{mol} \mathrm{L}^{-1}\right)$, where the detection limit is $0.54 \mu \mathrm{mol} \mathrm{L}{ }^{-1}(n=11)$. According to the guideline detection limit of the allowed maximum $\mathrm{Fe}^{3+}$ concentration $(5.4 \mu \mathrm{M})$ in drinking water proposed by the U.S. Environmental Protection Agency, ${ }^{\mathbf{3 0 , 6 0}}$ the lower detection limit reveals that CDs are credible fluorescent probes in the quantitative detection of trace amounts of $\mathrm{Fe}^{3+}$ in drinking water. From Table 1, the linear range and detection limit of our CD-based fluorescent nanoprobes are comparable to other nanoprobes, such as N-doped CDs obtained from microwave pyrolysis, ${ }^{42} \mathrm{~N}-$ doped CDs derived from Phyllanthus acidus and ammonia, ${ }^{57}$ and graphene quantum dots obtained by the acid oxidation of carbon black, ${ }^{59}$ which are the competition in the sensitive detection of $\mathrm{Fe}^{3+}$.
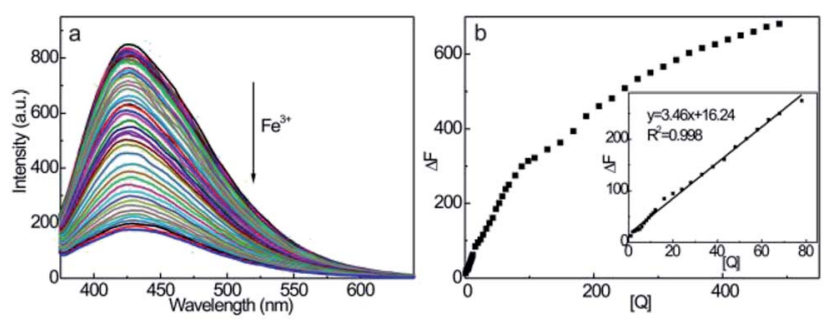

Fig. 7 (a) Fluorescence spectra of the $\mathrm{CDs}-\mathrm{Fe}^{3+}$ system at various $\mathrm{Fe}^{3+}$ concentrations $\left(1-488 \mu \mathrm{mol} \mathrm{L} \mathrm{L}^{-1}\right)$ and (b) linear relationship between $\Delta F$ and $\mathrm{Fe}^{3+}$ concentration $\left(1-78 \mu \mathrm{mol} \mathrm{L}{ }^{-1}\right) . C_{\mathrm{CDs}}=250 \mu \mathrm{g}$ $\mathrm{mL}^{-1}$.
Table 1 Comparison of the performances of CD-based fluorescent $\mathrm{Fe}^{3+}$ nanoprobes

\begin{tabular}{llll}
\hline Fluorescent materials & $\begin{array}{l}\text { Linear ranges } \\
(\mu \mathrm{M})\end{array}$ & $\begin{array}{l}\text { Detection limits } \\
(\mu \mathrm{M})\end{array}$ & Reference \\
\hline N,S co-doped CDs & $0-3.5$ & 0.017 & Ref. 1 \\
Polymer dots & $0.1-10$ & 0.0037 & Ref. 12 \\
N-CDs & $0-150$ & 0.5 & Ref. 16 \\
N-GQDs & $1-70$ & 0.08 & Ref. 18 \\
CDs & $0.02-40$ & 0.13 & Ref. 19 \\
CDs & $0.1-100$ & 0.016 & Ref. 23 \\
FNCDs & $2-25$ & 0.9 & Ref. 27 \\
S,N-CDs-PBA & $0.3-50$ & 0.1 & Ref. 28 \\
GQDs & $0-60$ & 0.45 & Ref. 29 \\
CDs & $0.05-10$ & 0.0137 & Ref. 31 \\
CDs & $1-78$ & 0.54 & This work \\
& & &
\end{tabular}

\section{Fluorescence quenching mechanism}

In general, the fluorescence quenching of fluorophores mainly originates from the static or dynamic interaction modes. In the static quenching mechanism, fluorophores and quenchers form a ground-state complex. The coordination or chelation interaction facilitates the partial transfer of excitation-state electrons from the CDs to the half-filled $3 \mathrm{~d}$ orbit of the central $\mathrm{Fe}^{3+}$ ions, which, therefore, inhibits the radiative transition back to the ground state, quenching the fluorescence of CDs. ${ }^{52}$ However, in dynamic quenching, the collision interactions between the quencher and excited fluorophores causes the nonfluorescent electrons to transfer from the donor to the acceptor, which, therefore, quenches the fluorescence of fluorophores. ${ }^{62}$ The fluorescence decay lifetime is recognized as a general criterion to primarily distinguish between static or dynamic pathways. ${ }^{61}$ From Fig. 5c, the average decay lifetime of $\mathrm{CD}-\mathrm{Fe}^{3+}(6.3 \mathrm{~ns})$ is almost the same as that of only CDs (6.2 ns), which implies that static quenching occurs between CDs and $\mathrm{Fe}^{3+}$. The UV-vis absorption spectrum was also measured (Fig. S10†); the absorbance of the CD-Fe ${ }^{3+}$ system substantially increases relative to the initial CD solution, showing high affinity of CDs toward $\mathrm{Fe}^{3+}$. The coordination or chelation interaction causes charge transfer transitions between the ligands and $\mathrm{Fe}^{3+}$, thereby resulting in additional absorbance. Further, this phenomenon evidences the formation of complexes between the CDs and $\mathrm{Fe}^{3+}$ to some extent. To gain further insights into the actual quenching mechanism of the $\mathrm{CD}-\mathrm{Fe}^{3+}$ system, the fluorescence emission intensities of the CD-Fe ${ }^{3+}$ system were analyzed according to Stern-Volmer equation (eqn (1)): ${ }^{63}$

$$
\frac{F_{0}}{F}=1+K_{\mathrm{q}} \tau_{0}[\mathrm{Q}]=1+K_{\mathrm{SV}}[\mathrm{Q}]
$$

where $F_{0}$ and $F$ represent the emission intensities in the absence and presence of $\mathrm{Fe}^{3+}$, respectively. Further, $K_{\mathrm{SV}}$ is the SternVolmer quenching constant, $K_{\mathrm{q}}$ is the bimolecular quenching rate constant, $\tau_{0}$ is the lifetime of a blank fluorophore, and [Q] is the concentration of the quencher. According to eqn (1), the $F_{0} /$ $F$ values demonstrate good linearity with [Q] over a wide concentration range (Fig. 8a). The regression equation can be 

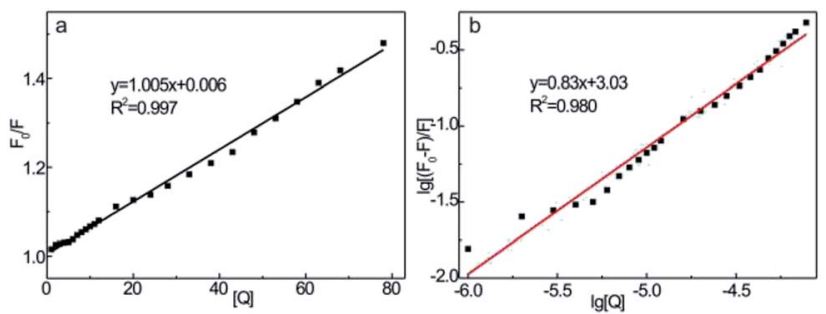

Fig. 8 (a) Stern-Volmer curves and (b) logarithmic plots of $\mathrm{CD}-\mathrm{Fe}^{3+}$ system. $C_{\mathrm{CDs}}=250 \mu \mathrm{g} \mathrm{mL}^{-1}, \mathrm{C}_{\mathrm{Fe}^{3+}}$ concentrations $(1,2,3,4,5,6,7,8,9$, $10,11,12,16,20,24,28,33,38,43,48,53,58,63,68$, and $\left.78 \mu \mathrm{mol} \mathrm{L}^{-1}\right)$.

expressed as follows: $F_{0} / F=1.005+0.006[\mathrm{Q}]\left(R^{2}=0.997 ; n=\right.$ 25). The $K_{\mathrm{SV}}$ value is determined as $0.006 \mathrm{~L} \mathrm{~mol}^{-1}$ from the slope of the regression straight line. Based on the fluorescence lifetime of CDs $(6.2 \mathrm{~ns}), K_{\mathrm{q}}$ is calculated to be $9.7 \times 10^{11} \mathrm{~L} \mathrm{~mol}^{-1}$ $\mathrm{s}^{-1}$. This value is 2 orders of magnitude higher over the limiting diffusion constant, $K_{\text {dif }}$, of the biomolecule $\left(K_{\text {dif }}=2.0 \times 10^{10} \mathrm{~L}\right.$ $\mathrm{mol}^{-1} \mathrm{~s}^{-1}$ ), which suggests that fluorescence quenching was trigged by a specific interaction between $\mathrm{CDs}$ and $\mathrm{Fe}^{3+}$. This, more accurately, is implied through the formation of a stable nonfluorescent complex. ${ }^{64}$ It is hypothesized that electrons in the excited state of CDs directly transfer to the unfilled orbits of $\mathrm{Fe}^{3+}$; the nonradiative electron transfer, therefore, quenches the intrinsic fluorescence of CDs.

In terms of the static quenching process, the number of binding sites $(n)$ and binding constant $(K)$ can be obtained according to eqn (2): ${ }^{65}$

$$
\lg \left(\frac{F_{0}-F}{F}\right)=\lg K+n \lg [\mathrm{Q}]
$$

From the linear plots shown in Fig. 8b, $K$ can be determined as $1.08 \times 10^{3} \mathrm{~L} \mathrm{~mol}^{-1}$ and $n=0.83\left(R^{2}=0.980\right)$. The moderate binding affinity between $\mathrm{CDs}$ and $\mathrm{Fe}^{3+}$ ions suggests the formation of a $\mathrm{CD}-\mathrm{Fe}^{3+}$ complex, which coincides with the UVvis and fluorescence lifetime results (Fig. S10† and 5c). Therefore, it is confirmed that the static-energy transfer from CDs to $\mathrm{Fe}^{3+}$ is responsible for the fluorescence quenching of CDs.

\section{Detection of $\mathrm{Fe}^{3+}$ in real water samples and serums}

To further verify the practicality of the proposed CD-based fluorescent nanoprobes for $\mathrm{Fe}^{3+}$ detection, $\mathrm{Fe}^{3+}$ in real water samples, including tap water, well water, Muye lake water in Xinxiang city, and serum samples were determined. The water samples were filtrated through a $0.22 \mu \mathrm{m}$ membrane and directly used as the solvent to prepare a neutral buffer solution to construct a CD-Fe ${ }^{3+}$-sensing system with known dosages of spiked $\mathrm{Fe}^{3+}$. As shown in Table 2, 90-103.3\% of spiked $\mathrm{Fe}^{3+}$ in the water samples can be recovered with low relative standard deviations $(0.07-0.37 \%)$ through fluorescence emission intensity detection upon six parallel trials, showing the feasibility of the $\mathrm{CD}$ fluorescent nanoprobes in the accurate detection of $\mathrm{Fe}^{3+}$ in real water samples. In the case of $\mathrm{Fe}^{3+}$ detection in the serum sample, known dosages of standard $\mathrm{Fe}^{3+}$ solution were spiked in the serum samples and were determined through the CD
Table $2 \mathrm{Fe}^{3+}$ assays in different water samples and serums

\begin{tabular}{|c|c|c|c|c|c|}
\hline \multirow[b]{2}{*}{ Analyte } & \multirow[b]{2}{*}{ Medium } & \multicolumn{2}{|c|}{$\begin{array}{l}\mathrm{Fe}^{3+} \\
\text { concentration } \\
(\mu \mathrm{M})\end{array}$} & \multirow{2}{*}{$\begin{array}{l}\text { Recovery } \\
(\%)\end{array}$} & \multirow[b]{2}{*}{$\operatorname{RSD}(\%, n=6)$} \\
\hline & & Added & Found & & \\
\hline \multirow[t]{3}{*}{$\mathrm{Fe}^{3+}$} & Human serum & 0 & & & 0.42 \\
\hline & & 8 & 7.47 & 93.4 & 0.20 \\
\hline & & 12 & 12.3 & 103.2 & 0.21 \\
\hline \multirow[t]{3}{*}{$\mathrm{Fe}^{3+}$} & Lake water & 0 & & & 0.35 \\
\hline & & 8 & 7.22 & 90.3 & 0.16 \\
\hline & & 12 & 11.79 & 98.2 & 0.14 \\
\hline \multirow[t]{3}{*}{$\mathrm{Fe}^{3+}$} & Tap water & 0 & & & 0.38 \\
\hline & & 8 & 7.25 & 90.6 & 0.18 \\
\hline & & 12 & 12.4 & 103.3 & 0.07 \\
\hline \multirow[t]{3}{*}{$\mathrm{Fe}^{3+}$} & Well water & 0 & & & 0.56 \\
\hline & & 8 & 7.2 & 90.0 & 0.37 \\
\hline & & 12 & 11.8 & 98.3 & 0.18 \\
\hline
\end{tabular}

fluorescent nanoprobe technique. Here, 93.4-103.2\% of the added $\mathrm{Fe}^{3+}$ in the serum samples can be recovered with standard deviations of about $0.2 \%$, which reconfirms the applicability of CD fluorescent nanoprobes for precise $\mathrm{Fe}^{3+}$ detection in blood samples. Given the low cost and simplicity in CDs preparation, the high sensitivity and low detection limit $\mathrm{Fe}^{3+}$ analysis; further, the excellent recoveries in $\mathrm{Fe}^{3+}$ detection in actual water samples and human serum, the proposed CD-based fluorescent nanoprobe is a promising candidate for the reliable and accurate detection of $\mathrm{Fe}^{3+}$ in environmental and clinical fields.

\section{Conclusions}

In summary, we have demonstrated a facile and low-cost onestep hydrothermal preparation of fluorescent CDs from fish scale precursors. The as-prepared CDs demonstrated high fluorescence activity with QY of $6.9 \%$, low cytotoxicity, and robust resistance against photobleaching and interferents, which enable their applications as fluorescent nanoprobes for the quantitative detection of $\mathrm{Fe}^{3+}$ with high sensitivity and selectivity through coordination and static quenching interactions. These CD-based fluorescent nanoprobes can also be extended toward the detection of $\mathrm{Fe}^{3+}$ in real water samples and human serums with good recoveries, showing the potential as a low-cost reliable fluorescent nanoprobe for environmental and clinical $\mathrm{Fe}^{3+}$ assays.

\section{Conflicts of interest}

There are no conflicts to declare.

\section{Acknowledgements}

This work was supported by NSFC (No. 21671059 and 51802084), Program for Innovative Research Groups in University of Henan Province (No. 18IRTSTHN002 and 18IRTSTHN003), 111 Project (No. D17007), Henan Center for 
Outstanding Overseas Scientists (No. GZS2018003), Scientific and Technological breakthrough project of Xinxiang City (CXGG17001) and Youth Fund of Henan Normal University (2017QK12).

\section{Notes and references}

1 C. Bolm, J. Legros, J. L. Paih and L. Zani, Chem. Rev., 2004, 104, 6217-6254.

2 Z. Q. Liu, Y. X. Zhang, L. X. Zhao, Z. J. Li, J. T. Wang, H. J. Li and L. M. Wu, Org. Lett., 2011, 13, 2208-2211.

3 F. A. Tezcan, J. T. Kaiser, D. Mustafi, M. Y. Walton, J. B. Howard and D. C. Rees, Science, 2005, 309, 1377-1380.

4 G. Cairo and A. Pietrangelo, Biochem. J., 2000, 352, 241-250. 5 D. Galaris, V. Skiada and A. Barbouti, Cancer Lett., 2008, 266, 21-29.

6 W. H. Hörl, J. Am. Soc. Nephrol., 2007, 18, 382-393.

7 G. Sucak, Z. Yegin, Z. Özkurt, S. Z. Ak, T. Karakan and G. Akyol, Bone Marrow Transplant., 2008, 42, 461-467.

8 S. Altamura and M. U. Muckenthaler, J. Alzheimer's Dis., 2009, 16, 879-895.

9 J. Q. Liu, H. B. Shentu, H. Y. Chen, P. Ye, B. Xu, Y. F. Zhang, H. Bastani, H. X. Peng, L. Chen and T. Q. Zhang, Water Res., 2017, 124, 353-362.

10 V. Gurnani, A. K. Singh and B. Venkataramani, Anal. Chem., 2003, 485, 221-232.

11 E. Wu and E. A. Boyle, Anal. Chem., 1998, 367, 183-191.

12 Y. Zhu, D. Pan, X. Hu, H. Han, M. Lin and C. Wang, Sens. Actuators, B, 2017, 243, 1-7.

13 S. Schaffer, P. Gareil, C. Dezael and D. Richard, J. Chromatogr. A, 1996, 740, 151-157.

14 J. H. Han, Z. Zhou, X. Bu, S. J. Zhu, H. Zhang, H. Z. Sun and B. Yang, Analyst, 2013, 138, 3402-3408.

15 J. Shen, S. M. Shang, X. Y. Chen, D. Wang and Y. Cai, Mater. Sci. Eng., C, 2017, 76, 856-864.

16 H. Ding, J. S. Wei and H. M. Xiong, Nanoscale, 2014, 6, 13817-13823.

17 C. R. Lohani and K. H. Lee, Sens. Actuators, B, 2010, 143, 649654.

18 T. G. Jo, J. M. Jung, J. Y. Han, M. H. Lim and C. Kim, $R S C$ Adv., 2017, 7, 28723-28732.

19 M. Q. Yu, Z. G. Zhu, H. Wang, L. Y. Li, F. Fu, Y. Song and E. Q. Song, Biosens. Bioelectron., 2017, 91, 143-148.

20 J. J. Jiang, P. F. Gao, Y. Zhang, G. M. Zhang, Y. Zhou, C. Dong and S. M. Shuang, Talanta, 2017, 174, 44-51.

21 M. J. Zhou, J. J. Guo and C. X. Yang, Sens. Actuators, B, 2018, 264, 52-58.

22 P. Wu, Y. Li and X. P. Yan, Anal. Chem., 2009, 81, 6252-6257.

23 S. N. Baker and G. A. Baker, Angew. Chem., Int. Ed., 2010, 49, 6726-6744.

24 S. T. Yang, L. Cao, P. J. G. Luo, F. S. Lu, X. Wang, H. F. Wang, M. J. Meziani, Y. F. Liu, G. Qi and Y. P. Sun, J. Am. Chem. Soc., 2009, 131, 11308-11309.

25 J. C. Liu, J. K. Ren, Z. Xie, B. Guan, J. X. Wang, T. Ikeda and L. Jiang, Nanoscale, 2018, 10, 4642-4649.

26 S. Y. Liu, N. Zhao, Z. Cheng and H. G. Liu, Nanoscale, 2015, 7, 6836-6842.
27 Z. P. Zeng, S. F. Chen, T. T. Y. Tan and F. X. Xiao, Catal. Today, 2018, 315, 171-183.

28 S. Sahu, B. Behera, T. K. Maiti and S. Mohapatra, Chem. Commun., 2012, 48, 8835-8837.

29 H. Huang, Y. Xu, C. J. Tang, J. R. Chen, A. J. Wang and J. J. Feng, New J. Chem., 2014, 38, 784-789.

30 V. N. Mehta, S. Jha, H. Basu, R. K. Singhal and S. K. Kailasa, Sens. Actuators, B, 2015, 213, 434-443.

31 X. Feng, Y. Q. Jiang, J. P. Zhao, M. Miao, S. M. Cao, J. H. Fang and L. Y. Shi, RSC Adv., 2015, 5, 31250-31254.

32 B. D. Yin, J. H. Deng, X. Peng, Q. Long, J. N. Zhao, Q. J. Lu, Q. Chen, H. T. Li, H. Tang, Y. Y. Zhang and S. Z. Yao, Analyst, 2013, 138, 6551-6557.

33 M. J. Krysmann, A. Kelarakis and E. P. Giannelis, Green Chem., 2012, 14, 3141-3145.

34 L. Wang, H. S. Zhou and A. Chem, Anal. Chem., 2014, 86, 8902-8905.

35 Z. Y. Gao, X. R. Wang, J. L. Chang, D. P. Wu, L. Wang, X. Liu, F. Xu, Y. M. Guo and K. Jiang, RSC Adv., 2015, 5, 4866548674.

36 S. Y. Park, H. U. Lee, E. S. Park, S. C. Lee, J. W. Lee, S. W. Jeong, C. H. Kim, Y. C. Lee, Y. S. Huh and J. Lee, ACS Appl. Mater. Interfaces, 2014, 6, 3365-3370.

37 G. S. Tong, J. X. Wang, R. B. Wang, X. Q. Guo, L. He, F. Qiu, G. Wang, B. S. Zhu, X. Y. Zhu and T. Liu, J. Mater. Chem. B, 2015, 3, 700-706.

38 T. Rustad, J. Environ. Agric. Food Chem., 2003, 4, 458-463.

39 V. Manikkam, M. L. Mathai, W. A. Street, O. N. Donkor and T. Vasiljevic, Food Res. Int., 2016, 23, 1614-1622.

40 X. D. He, H. T. Li, Y. Liu, H. Huang, Z. H. Kang and S. T. Lee, Colloids Surf., B, 2011, 87, 326-332.

41 Z. C. Yang, M. Wang, A. M. Yong, S. Y. Wong, X. H. Zhang, H. Tan, A. Y. Chang, X. Li and J. Wang, Chem. Commun., 2011, 47, 11615-11617.

42 C. Wang, T. T. Hu, Z. Q. Wen, J. D. Zhou, X. J. Wang, Q. Wu and C. X. Wang, J. Colloid Interface Sci., 2018, 521, 33-41.

43 S. Sahu, B. Behera, T. K. Maiti and S. Mohapatra, Chem. Commun., 2012, 48, 8835-8837.

44 Y. P. Hu, J. Yang, J. W. Tian, L. Jia and J. S. Yu, Carbon, 2014, 77, 775-782.

45 H. B. Xu, S. H. Zhou, L. L. Xiao, H. H. Wang, S. Z. Li and Q. H. Yuan, J. Mater. Chem. C, 2015, 3, 291-297.

46 T. T. Xu, J. X. Yang, J. M. Song, J. S. Chen, H. L. Niu, C. J. Mao, S. Y. Zhang and Y. H. Shen, Sens. Actuators, B, 2017, 243, 863872.

47 W. Liu, H. P. Diao, H. H. Chang, H. J. Wang, T. T. Li and W. L. Wei, Sens. Actuators, B, 2017, 241, 190-198.

48 Y. B. Wang, Q. Chang and S. L. Hu, Sens. Actuators, B, 2017, 253, 928-933.

49 Y. Zhang, Z. Y. Gao, W. Q. Zhang, W. Wang, J. L. Chang and J. Kai, Sens. Actuators, B, 2018, 262, 928-937.

50 S. Liu, J. Q. Tian, L. Wang, Y. W. Zhang, X. Y. Qin, Y. L. Luo, A. M. Asiri, A. O. Al-Youbi and X. P. Sun, Adv. Mater., 2012, 24, 2037-2041.

51 P. J. S. Rana, P. Singh and P. Kar, J. Mater. Chem. B, 2016, 4, 5929-5937. 
52 G. Gao, Y. W. Jiang, H. R. Jia, J. J. Yang and F. G. Wu, Carbon, 2018, 134, 232-243.

53 B. F. Shi, Y. B. Su, L. L. Zhang, M. J. Huang, R. J. Liu and S. L. Zhao, ACS Appl. Mater. Interfaces, 2016, 8, 10717-10725.

54 Y. H. Yang, J. H. Cui, M. T. Zheng, C. F. Hu, S. Z. Tan, Y. Xiao, Q. Yang and Y. L. Liu, Chem. Commun., 2012, 48, 380-382.

55 M. J. Krysmann, A. Kelarakis, P. Dallas and E. P. Giannelis, J. Am. Chem. Soc., 2012, 134, 747-750.

56 R. Atchudan, T. N. J. I. Edison, K. R. Aseer, S. Perumal, N. Karthik and Y. R. Lee, Biosens. Bioelectron., 2018, 99, 303-311.

57 Y. P. Sun, B. Zhou, Y. Lin, W. Wang, K. A. S. Fernando, P. Pathak, M. J. Meziani, B. A. Harruff, X. Wang, H. F. Wang, P. G. Luo, H. Yang, M. E. Kose, B. L. Chen, L. M. Veca and S. Y. Xie, J. Am. Chem. Soc., 2006, 128, 7756-7757.

58 C. J. Li, Y. Q. Wang, X. J. Zhang, X. L. Guo, X. X. Kang, L. B. Du and Y. Liu, J. Colloid Interface Sci., 2018, 526, 487496.
59 X. W. Zhu, Z. Zhang, Z. J. Xue, C. H. Huang, Y. Shan, C. Liu, X. Y. Qin, W. S. Yang, X. Chen and T. Wang, Anal. Chem., 2017, 89, 12054-12058.

60 C. X. Wang, Y. J. Huang, K. L. Jiang, M. G. Humphrey and C. Zhang, Analyst, 2016, 141, 4488-4494.

61 M. Shamsipur, K. Molaei, F. Molaabasi, M. Alipour, N. Alizadeh, S. Hosseinkhani and M. Hosseini, Talanta, 2018, 183, 122-130.

62 T. Madrakian, S. Maleki, S. Gilak and A. Afkhami, Sens. Actuators, B, 2017, 247, 428-435.

63 G. F. Shen, T. T. Liu, Q. Wang, M. Jiang and J. H. Shi, J. Photochem. Photobiol., B, 2015, 153, 380-390.

64 Y. H. Liu, W. X. Duan, W. Song, J. J. Liu, C. L. Ren, J. Wu, D. Liu and H. L. Chen, ACS Appl. Mater. Interfaces, 2017, 9, 12663-12672.

65 Y. S. Yuan, J. Jiang, S. P. Liu, J. D. Yang, H. Zhang, J. J. Yan and X. L. Hu, Sens. Actuators, B, 2017, 242, 545-553. 